\title{
Strategic Thinking and Performance of Small and Medium- Sized Dairy Processing Firms in Kenya
}

\author{
Joyce Muthoni Mbaya \\ Samuel Maina \\ Mary Namusonge
}

School of Business, Kenyatta University, Nairobi, Kenya

Doi:10.19044/esj.2021.v17n8p106

Submitted: 08 January 2021

Accepted: 10 March 2021

Published: 31 March 2021
Copyright 2021 Author(s)

Under Creative Commons BY-NC-ND

4.0 OPEN ACCESS

Cite As:

Mbaya, MJ., Maina, S., and Namusonge, M. (2021). Strategic Thinking and Performance of Small and Medium-Sized Dairy Processing Firms in Kenya. European Scientific Journal, ESJ, 17(8), 106.https://doi.org/10.19044/esj.2021.v17n8p106

\begin{abstract}
The dairy sector plays a crucial role in economic growth and development of Kenya. However, many firms in the sector, especially the small and medium-sized, continue to face performance challenges such as competition from unregulated informal milk market, accessing markets and high industry barriers among others. A review of literature shows that the effect of strategic thinking on the performance of small and medium-sized dairy processing firms remains uncertain. This study sought to determine the effect of strategic thinking and performance of small and medium-sized dairy processing firms in Kenya. The study was anchored on the Leidtka Model. Positivism research philosophy was adopted. Descriptive and explanatory research designs were used. A census survey was conducted on all the small and medium-sized dairy processing firms in Kenya and primary data was collected. Descriptive statistics such as mean and standard deviation were used to explain data characteristics, while multiple regression was used to test the effect of the study variables on firm performance. The results showed that strategic thinking has a positive significant effect on the performance of small and medium-sized dairy processing firms in Kenya, thus it was perceived that strategic thinking aids creation of a path for what the firm wants to become through focusing on their intent, systems, timely thinking, intelligent opportunism and hypothesis-driven research. The study contributes to the body of knowledge by filling contextual, empirical, and conceptual gaps identified earlier in literature and establishing a nexus of strategic thinking and performance of small and medium-sized dairy processing firms in Kenya. The study recommends that strategic thinking should be enhanced particularly by using research to inform their decision-making
\end{abstract}


and practice quick decision-making to mitigate or exploit opportunities while thinking of possible solutions to unexpected challenges.

Keywords: Strategic thinking, Firm performance, Small and medium-sized dairy processing firms

\section{Introduction}

Strategic thinking expresses the capability of leaders to be creative in dealing with opportunities or threats, weaknesses and strengths facing the firm. Strategic thinking is a process whereby the top management of a firm create paths for what the firm desires to become (Olaniyi \& Elumah, 2016). Carter and Greer (2013) indicate that strategic thinking is the root of the strategy aimed at providing a clear course of action for the organization by focusing on a phenomenon, how it should happen and how it unfolds. Strategic thinking may also be viewed from the perspective of a pre-planned action that is meant to improve a firm's performance (Emran \& Emamgholizadeh, 2015). In exploring the strategic thinking paradigm, Liedtka (1998) argues that strategic thinking contains five elements, which are, systems perspective, intent focus, intelligent opportunism, thinking in time and hypothesis-driven perspective. A systems perspective involves a firm's attempt to describe the structure in which it exists through the collection of the right information and prioritizing the features of the structure that may influence its operations in the present time and in the future.

The strategic intent, (also known as the intent focus) allows persons in a firm to direct their attention towards the firm's goals, resisting distractions and concentrating on firm goals until they are achieved, (Casey \& Goldman, 2010). According to Leidkta (1998), thinking in time involves the connection of the past to the present and the future and also learning from the past, then using what was learned to make predictions to assess the gap between the present and the future. Intelligent opportunism focuses on the ability to notice and exploit opportunities. The hypothesis-driven perspective involves generating questions that enables a firm to envisage various scenarios, analyse them grounded on their accumulated knowledge and then the best hypotheses or experiment is assessed.

Small and medium-sized dairy processing firms need strategic leaders who scan both their internal and external environments, understand the systems that are likely to affect their future operations, and thus focus their energies towards achievement of goals while consecutively taking lessons from past experiences to forecast the future. Also, these small and medium-sized dairy processing firms need strategic leaders who can detect and exploit opportunities as they emerge and critically evaluate such opportunities based on previously acquired knowledge and experiences. For this reason, the study 
adopts the Liedtka (1998) five elements: systems perspective, intent focus, intelligent opportunism, thinking in time and hypothesis-driven thinking model to operationalise strategic thinking.

\section{Statement of the problem}

The dairy industry in Kenya according to KDB (2015), is one of the best industries in Africa, with thirty milk processors with a range of products and contributing four percent of Kenya's Gross Domestic Product (GDP). The sector in Kenya has metamorphosed from a monopolistic market owned by the Kenya Government through Kenya Co-operative Creameries (KCC). The cooperative system significantly led to the development and growth of KCC which monopolised the market until 1992, when the industry was liberalised, (Wambugu, Kirimi \& Opiyo, 2011). This led to an influx of privately-owned dairy processing firms, many being small-scale processors.

Since the liberalization, the number of dairy processing firms increased from KCC to 30 by December 2018. Of these 30 firms, there are 7 large dairy processing firms while the rest are medium to small dairy processing firms. According to the Kenya Dairy Board (2018), firms that process over 40,000 litres of milk per day are considered large, between 20,000 litres and 40,000 litres are medium-sized while those that process less than 20,000 litres but more than 1,000 litres daily are categorised to be small dairy processing firms. The small and medium-sized dairy processors in Kenya are however, being predated by the large companies. For instance, Brookside dairy that processes 750,000 litres of milk daily, has organically grown from a small dairy in 1993, and acquired other processors such as Delamere Dairy, Ilara Dairy, Buzeki Dairy and Spin Knit Dairy (Food Business Africa, 2015). This dominance and predation have made it difficult for small processors to thrive through the competition to become large companies. Additionally, the predation has led to an increase in processors owning milk sources from farms to factories, acquiring, distributing and get into retail spaces in the major outlets. As such, the industry is increasingly becoming a heavy investment industry, with the smaller players being pushed out of business by the large processors who have access to internal and external sources of funds. This means that the industry is gradually erecting barriers of entry that younger firms will be unable to crack, and more medium processors being bought out (Kraja and Osmani, 2013).

Despite the crucial role of the dairy sector in economic growth and development of Kenya, several firms in the sector, especially the small and medium-sized, continue to face performance challenges (Wambugu \& Kimuyu, 2017). Staal, Pratt and Jabbar, (2008) indicate that a poorly managed formal milk market fails to provide an effective link between farmers and consumers as compared to the informal milk market, thus implying a poor performance of small and medium-sized dairy processing 
firms. According to Kariuki, Iravo and Kihoro, (2015), the unregulated informal milk market sells approximately $56 \%$ of the $70 \%$ of the country's marketed milk. The remaining $14 \%$ is sold by registered milk processing firms, out of which $85 \%$ is processed by five large processing firms' processing more than 100,000 litres daily. These dairies consist of Brookside Dairy, New KCC, Githunguri Dairy Farmers Co-operative Society, Sameer Agriculture and Livestock, and Countryside Dairy. This leaves only 15\% for small and medium-sized dairy firms to process, despite their large numbers. This not only reflects a dismal performance in terms of efficiency and effectiveness of the small and medium-sized dairy processing firms but also a reduced market share.

Several studies have been carried out on the relationship between strategic thinking and performance.-The conceptualization of strategic thinking has varied from study to study where some have operationalized it through conceptual thinking, systematic approach, cognition, and opportunism among others (Mahdavian, Mirabi \& Haghshenas, 2014; Ali, 2015; Ohola, 2016). Additionally, the studies have been conducted in other countries and contexts (Salih \& Alnaji, 2014; Mahdavian, Mirabi \& Haghshenas, 2014; Ali, 2015; Olaniyi \& Elumah 2016), while others have related strategic thinking to variables such as strategic agility, the sustainability of strategic thinking, transformational leadership, strategic management practices and not firm performance (Salih \& Alnaji, 2014; Mahdavian, Mirabi \& Haghshenas, 2014; Ali, 2015; Ohola, 2016). The methodology used has also varied (Ali, 2015; Ohola, 2016). As such, this study establishes the existence of contextual, conceptual and empirical gaps in literature. This study therefore sought to fill these gaps by investigating the effect of strategic thinking on performance of small and medium-sized dairy processing firms in Kenya.

\section{Literature review}

\subsection{Theoretical Literature review}

Strategic thinking is viewed from different perspective to mean thinking about strategy (Wilson, 2010), a way of thinking with precise and noticeable characteristics (Mintzberg \& Lampel, 1999). Similarly, Stacey (1992) views strategic thinking as the use of analogies and qualitative connections in the development of new creative ideas and formulating actions from new knowledge perspectives. From this point of view, strategic thinking is deduced to involve thinking and taking action based on specific suppositions and possible action options, and challenging assumptions and actions that are in existence which lead to the creation of newer and more suitable choices, (Schoemaker, Krupp \& Howland, 2013).

Leidtka (1998) developed a strategic model based on the Mintzberg (1994) model and viewed strategic thinking from five perspectives, that is, 
systems perspective, intent focus, intelligent opportunism, thinking in time and hypothesis-driven perspective.

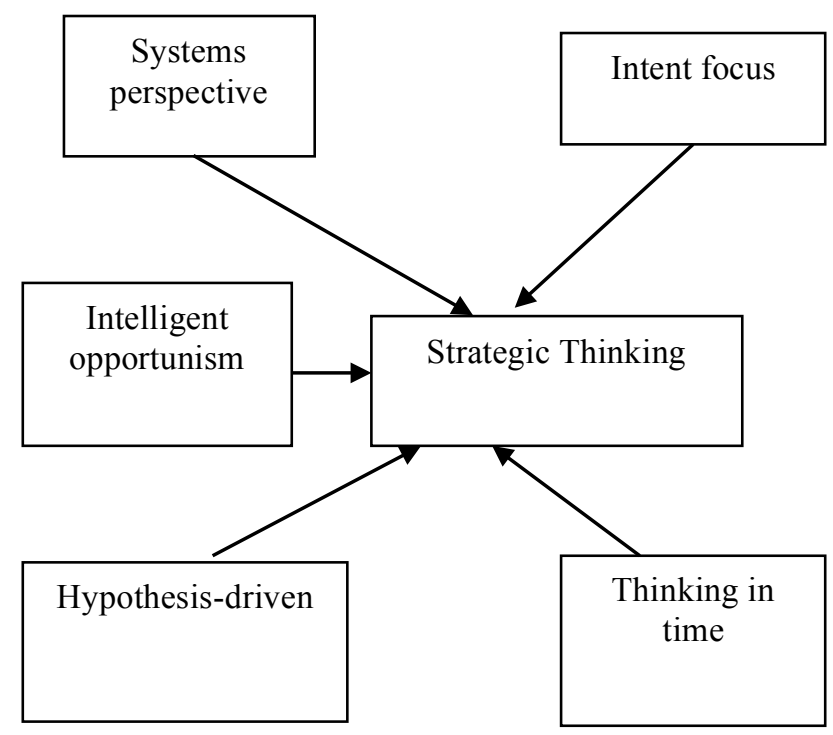

Figure 1: The Leidtka Strategic Thinking model Source: Leidtka (1998)

According to the model, systems perspective sees a strategic thinker as one with a mental model of creating value from the beginning to the end with a clear understanding of the existing interdependencies within the value chain. In this sense, the leader has to include the understanding of the firm's external and internal environments that facilitates innovation (Serfontein, 2010). Consequently, the strategic thinker stays open to emergent prospects. Strategic intent on the other hand, is about a particular viewpoint of the market in the long-term and the competitive edge which a firm intends to create (Feyzollah \& Saeid, 2015).

Intelligent opportunism involves being open to novel experiences that enable a firm yield advantages of alternate strategies which emerge that are more applicable to a dynamic business environment. According to Mintzberg (1999), this tactic is underscored by the contrast between the emerging and deliberate strategies. However, Serfontein (2010), points out that connecting the present and the past, and linking that with the future, is thinking in time. Hypothesis-driven thinking involves embracing a hypothesis and testing the core activities as well as raising queries which lead a firm to contemplate and analyse different scenarios. Liedtka (1998) points out that strategic thinkers stay open to emergent opportunities and firms which can include a capacity for thinking strategically in the entire firm, will have generated a different basis of competitive advantage. To support strategic thinking in this study, the Liedtka model was used and measured in terms of intent focus, systems 
perspective, timely thinking, intelligent opportunism, and hypothesis-driven perspective.

\subsection{Empirical Literature review}

Salih and Alnaji (2014) aimed to study the connection between strategic thinking, strategic agility, and strategic performance. The study was carried out in Jordanian insurance companies. The results indicated that strategic agility and thinking effect the performance of insurance companies of Jordan. Similarly, Olaniyi and Elumah (2016) employed the Pearson moment correlation coefficient to find out the link between strategic thinking and firm performance and found that a positive relationship exists between strategic thinking and firm performance. However, it was observed that the strongest link was in the relationship between strategic thinking and strategic performance was mediated by strategic agility.

Mahdavian, Mirabi and Haghshenas (2014) sought to determine the impact of strategic thinking on the performance of Mashhad municipal managers. Analysis of data was done following descriptive statistics while correlation analysis was used for inferential analysis. The statistical population for this study included all the 90 senior managers of Mashhad Municipality. The outcome of the research was that strategic thinking operationalised through conceptual thinking, systematic approach, foresight, opportunism, cognition and transformational leadership improved performance among municipal managers of Mashhad City. The findings of the study apply to the current study even if they concentrated on the direct association of concerning strategic thinking and occupational performance.

Ali (2015) studied the role of sustainability in strategic thinking. The study was carried out in Norway in the ship building industry. The study aimed at reducing the gap between the process of strategic thinking and sustainability. A case study approach was used, and the collection of data was done through interviewing method. The findings indicated the need for innovation in the methods used in production for improved performance on both financial and environmental aspects. The study leaned more on innovative production concepts which are potentially applicable in the industry. However, the study differs in the methodological dimension in that a case study was used. Additionally, strategic thinking was considered as a dependent variable while it is an independent variable in the current study. Congruently, Ohola (2016), through a case study, carried out a research on strategic thinking and strategic management practices by Boogaart Betonpompen in Holland. Data collection was done by use of an interview guide on the Chief Executive Officer. It was established that strategic thinking influences strategic management practices at the company and that the employees are key in the process of strategy. The importance of 
flexibility in adapting to new developments in the environment was seen in the results. The importance of emergent strategies in effective decisionmaking was also seen. The findings established the importance of scanning the environment keenly and continuously and using real-time information in decision-making. A discussion of the study's result showed a link concerning strategic thinking and strategic management practices. However, the study varies from the current study in that a case study was used and only the Chief Executive Officer was interviewed, thus could suffer from a single source for information. The current study is a cross-sectional survey and managerial level leaders are the respondents.

From the reviewed theoretical and empirical literature, the current study established that there is limited literature on strategic thinking especially in the Kenyan context. Although the studies gave an insight to the various strategic thinking variables that affect performance, the studies were majorly carried out in the developed countries with differing methodologies (Ali, 2015; Ohola, 2016). The conceptualization of strategic thinking was also varied (Salih \& Alnaji, 2014; Mahdavian, Mirabi \& Hagshenas, 2014; Olaniyi \& Elumah, 2016). From the varied and vast literature review conducted, the conceptual framework in Figure 2 was developed.

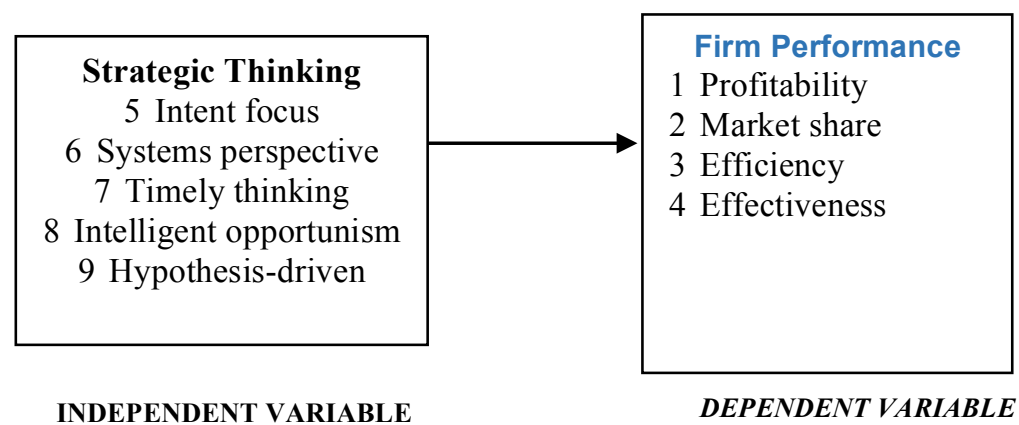

\section{Figure 2: Conceptual Framework}

Source: Author (2019)

Figure 2 illustrates the conceptual framework developed from reviewed literature. Strategic thinking is the independent variable, while firm performance, measured through profitability, market share, efficiency and effectiveness. The study hypothesised that:

$H_{01}$ : Strategic thinking has no significant effect on performance of small and medium-sized dairy processing firms in Kenya. 


\section{Research Methodology}

Research philosophy is a belief about ways that data on a phenomenon should be collected, analysed and used, (Bajpal, 2011). Epistemology is the study of the development of knowledge that is acceptable in a field of study, (Bryman, 2012). This study was guided by a positivism epistemological research philosophy. The positivist research philosophy enables researchers to empirically test hypotheses to establish facts, (Koul, 2008). This research philosophy is found applicable since the study tests a hypothesis to form decisions on the relationships existing amongst the variables under study. Further, the positivism philosophy involves working with observable social realisms and quantifiable observations whose results can be generalised, and allows use of structured methodology to allow replication, (Saunders, Lewis $\&$ Thornhill, 2009). Additionally, the positivism philosophy upholds factual and non-abstract knowledge therefore predictions on knowledge are based on what is observed and experimented (Robson \& Neuman, 2014). In line with this postulation, this study collected factual data which was analysed using available models to extract their meaning to confirm or disapprove the existing knowledge. As outlined in the philosophy, the findings of the current study are grounded on quantitative data from small and mediumsized dairy processing firms in Kenya.

The study used both cross-sectional survey and explanatory research designs as recommended by Saunders, Lewis and Thornhill (2009). Crosssectional survey design is used for descriptive research and allows the collection of large amounts of data economically from a sizeable population through questionnaires at a time. Additionally, Kothari (2004) indicates that a cross-sectional survey is concerned with hypothesis construction and testing and can be used in a census survey, which is used in the current study. Sekaran and Bougie (2016) highlight that explanatory research design is used in the assessment of the consequence of certain variations of a norm or process while focusing on the analyses of a situation or problems to illustrate the linkages in variables. As noted by Saunders (2011), explanatory study establishes causal relationships between variables. Sekaran and Bougie (2010) note that explanatory research design is used in assessing the effect of precise changes on prevailing processes and focuses on analysis of a situation or problem to explain relationship patterns between variables. Based on these reasons, the explanatory research design was found suitable in identifying the degree and feature of cause and effect relationship present between strategic thinking and performance of small and medium-sized dairy processing firms in Kenya.

The targeted population was all the 23 small and medium-sized dairy processing firms in Kenya as registered by the Kenya Dairy Board of Kenya as of December 31, 2018. A census survey of all the 23 small and mediumsized dairy processing firms registered by the Kenya Dairy Board was used. 
Four functional areas from each of the small and medium-sized dairy processing firms were identified consisting of the Chief Executive Officer, finance manager, marketing manager and production manager. The total sample size was therefore 92 respondents. Primary data was collected by the use of self-administered questionnaires administered using the drop-andpick-later method as recommended by Mugenda (2008). According to Lewis (2015) questionnaires are preferred in data collection because information can be collected from a large portion of a population. In addition, they enable the examination and explanation of relationships between variables. Goodman, Cryder and Cheema (2013) advocate the use of questionnaires because they enable the collection of data in a relatively short time, at a lower cost, and enable the generation of findings that are representative of the whole population. In order to give adequate time for responses, questionnaires were dropped and picked from respondents according to recommendations by Lewis (2015). Research assistants booked appointments with respondent's firm's prior to meeting the respondents for questionnaire administration. The research assistants administered the questionnaires to respondents to establish rapport, clarify the reason for the research and make any other clarifications that may have been necessary, as guided by recommendations by Mugenda (2008). The research assistants who were engaged in data collection were trained on creation of rapport with the respondents and how to convince the respondents to give relevant data and how to seek clarifications where needed.

The questionnaire had both open-ended and closed questions. The closed questions were used since they let respondents respond from few stated options. The closed or structured questions were also preferred since they are generally easier to evaluate (Lampard \& Pole, 2015). The closed questions were of a five-point Likert scale format as recommended by Boone and Boone (2012) and Kuen (2012). To encourage respondents to give deeper responses, open-ended questions were used to get any information not highlighted in the closed questions. This was based on recommendation by Saunders (2011), that open-ended or unstructured questions permit respondents to give thoughtful responses.

Pilot test data from the sample of 10 employees in selected dairy processing firms was used in testing reliability of the questionnaire. The purpose of the pilot test was to establish face and content validity of the questionnaire in conjunction with the opinions sought from professionals and experts in the field of investigation as recommended by Mugenda, (2008). According to Saunders, Lewis and Thornhill (2009), content validity tests if the research instrument precisely assesses features of variables of the study in conformation with relevant theory. Component Factor Analysis (CFA) was used to test how well the variables of strategic thinking represent the number of constructs. It was found that the Item content Validity Index for 
strategic thinking was 0.860. According to Polit and Beck (2006), a content validity index of above 0.80 is considered acceptable and a content validity index equal 1.00 is considered excellent. Overall, the content validity index for the variables was 0.860 which is greater than the threshold of 0.80 indicating that the research instrument was valid. The reliability of the questionnaire was measured through Cronbach Alpha, where a coefficient of greater than 0.7 was accepted as reliable. According to Mugenda (2008), a coefficient of 0.7 is a commonly accepted rule of thumb that indicates acceptable reliability. The results were as shown in Table 1.

Table 1: Reliability Coefficients

\begin{tabular}{lll}
\hline Variable & Cronbach's Alpha \\
\hline & $\begin{array}{l}\text { Cronbach } \\
\text { Coefficients }\end{array}$ & AlphaRemarks \\
\hline Strategic thinking & 0.882 & Reliable \\
Firm Performance & 0.934 & Reliable \\
Overall & 0.820 & Reliable \\
\hline
\end{tabular}

Source: Research Data (2019)

From these results in Table 1, all the variables had a Cronbach's alpha coefficient greater than 0.7 . Therefore, basing on the recommendations by Mugenda (2008), the research instrument was found to be reliable.

Analyses of data was done using both descriptive and inferential statistics. All analyses was aided by the Package for the Social Sciences (SPSS). Descriptive statistics was used to summarise the survey data and included means and standard deviations, while inferential statistics involved regression analysis and was used for testing the hypothesis and drawing conclusions. Inferential data analysis was conducted using Pearson correlation coefficient and multiple regression analysis. Multiple regression analysis was done and interpreted through adjusted $\mathrm{R}^{2}$ values and $\mathrm{p}$-values at $\mathrm{P}<0.05$ significance level, that is, the results were at $95 \%$ confidence level as advocated by Mugenda and Mugenda (2003), since it is the level generally used in business and social research.

\section{Descriptive Statistics}

The descriptive statistics that summarized the major characteristics of the study variables were mean scores and standard deviation.

\subsection{Strategic Thinking}

The study sought to establish the extent to which strategic thinking affects the performance of small and medium-sized dairy processing firms in Kenya. The descriptive statistics are presented in Table 2. 
Table 2: Descriptive Statistics for Strategic Thinking

\begin{tabular}{|c|c|c|}
\hline J & Mean & $\begin{array}{l}\text { Standard } \\
\text { Deviation }\end{array}$ \\
\hline The decisions of the firm are informed by research 84 & 4.38 & .820 \\
\hline $\begin{array}{l}\text { Current happenings in the industry affect decision- } 84 \\
\text { making in the firm }\end{array}$ & 4.08 & .698 \\
\hline $\begin{array}{l}\text { The firm prioritises the organisational structure to } \\
\text { influence present and future operations }\end{array}$ & 3.71 & .900 \\
\hline $\begin{array}{l}\text { The firm encourages thinking of possible solutions } \\
\text { to unexpected challenges }\end{array}$ & 3.60 & .899 \\
\hline $\begin{array}{l}\text { The firm creates scenarios to assist in } \text { making }_{84} \\
\text { decisions }\end{array}$ & 3.51 & .898 \\
\hline $\begin{array}{l}\text { The firm takes quick advantage of changes in the } \\
\text { environment }\end{array}$ & 3.18 & .906 \\
\hline $\begin{array}{l}\text { Past experiences of the firm are considered } \text { when }_{84} \\
\text { making decisions }\end{array}$ & 3.06 & .912 \\
\hline $\begin{array}{ll}\text { The firm is open to new experiences } & 84\end{array}$ & 3.06 & .944 \\
\hline $\begin{array}{l}\text { Changes or actions in the firm are suspended until } \\
\text { necessary information is gathered }\end{array}$ & 2.92 & .953 \\
\hline Aggregate mean score and standard deviation & 3.50 & .881 \\
\hline
\end{tabular}

Table 2 indicates that the respondents agreed to a large extent that the decisions of the firms were informed by research and that the current happenings in the industry affect their decision-making as indicated by mean scores of 4.38 and 4.08 respectively. The respondents however had varied opinions that decisions of the firm are informed by research as indicated by a standard deviation of 0.820 . Also, the respondents agreed to a large extent that the small and medium-sized dairy processing firms prioritise the organisational structure to influence present and future operations, encourages thinking of possible solutions to unexpected challenges and that they create scenarios to assist in making decisions as shown by the respective mean scores of 3.71, 3.60 and 3.51. However, high standard deviations of $0.900,0.899$ and 0.898 indicate that the respondents had variations in their opinions concerning the three aspects.

The study also established that the respondents agreed to a moderate extent that dairy firms take quick advantage of changes in the environment; the firm considers past experiences when making decisions and firms are open to new experiences as indicated by their mean scores of 3.18, 3.06 and 3.06 respectively. On the contrary, these statements had high standard deviations of $0.906,0.912$ and 0.944 respectively, indicating that there were high variations in the respondent's opinions. The respondents agreed to a 
little extent that changes or actions in the firm are suspended until the necessary information is gathered, as indicated by a mean score of 2.92 and a standard deviation of 0.953 which indicates a high variation in responses.

Overall, the respondents agreed to a large extent that strategic thinking is present in the small and medium-sized dairy processing firms as shown by an aggregate mean of 3.50. A standard deviation of 0.881 indicates that the respondents had varied opinions on the role that strategic thinking plays in firm performance.

\section{Inferential Analysis}

The study sought to determine the effect of strategic thinking on performance of small and medium-sized dairy processing firms in Kenya. The corresponding hypothesis stated that strategic thinking has no significant effect on the performance of small and medium-sized dairy processing firms in Kenya. To test this hypothesis, multiple regression analysis was done and interpreted through adjusted probability values ( $\mathrm{p}$-values) at $\mathrm{P}<0.05$ significance level. According to Di Leo and Sardanelli (2020), a 0.05 significance level is a conventionally accepted threshold to distinguish significant from non-significant outcomes and the smaller the calculated pvalue, the more improbable the null hypothesis will be and vice-versa. The study used an empirical model to test the statistical significance of the relationship between strategic thinking and performance of small and medium-sized dairy processing firms in Kenya. Multiple regression model was used to analyze the effect of the independent variables on the dependent variable. Multiple regression models establish the line of best fit and is an accurate model for describing the relationship between the independent and dependent variables, (Field, 2013). The model was found appropriate since the dependent variable is a continuous variable. The direct relationship between strategic thinking and firm performance was done using the regression model below:

$$
\text { Performance }=0.56+0.225 \text { strategic thinking }
$$

The results are shown in Table 3.

\begin{tabular}{llllll}
\hline & B & Standard Error & Beta & & \\
\hline & Model & $\begin{array}{l}\text { Unstandardized } \\
\text { Coefficients }\end{array}$ & $\begin{array}{l}\text { Standardized } \\
\text { Coefficients }\end{array}$ & T & Sig. \\
(Constant) & .056 & .086 & & .655 & .514 \\
$\begin{array}{l}\text { Strategic } \\
\text { Thinking }\end{array}$ & .225 & .019 & .357 & 11.996 & .000 \\
\hline
\end{tabular}

Table 3: Coefficients ${ }^{\mathrm{a}}$ for Multiple Regression 
a. Dependent Variable: Performance

Source: Survey Data (2019)

The results in Table 3 show that the adjusted coefficient of multiple determination, $\beta=0.56$. This means that if all other factors are held constant, the performance of small and medium-sized dairy processing firms would be 0.56 . Also, coefficient of strategic thinking is 0.225 meaning that if all other factors are held constant and strategic thinking is increased by a unit, there would be a 0.225 increase in the performance of small and medium-sized dairy processing firms in Kenya. Strategic thinking has a pvalue of $0.000<0.05$ level of significance. Based on the P-value, the study rejects the null hypothesis and concludes that strategic thinking has a positive significant effect on performance of small and medium-sized dairy processing firms in Kenya. It is also noted that the findings of the study indicate that the T-values for strategic thinking is greater than the T-critical (1.664), calculated at 0.05 level of significance, thus found to be significant in predicting the performance of small and medium sized dairy processing firms in Kenya.

The results obtained in this variable were consistent with Mahdavian, Mirabi and Haghshenas (2014) study that strategic thinking improved performance among managers. Similarly, Ohola (2016) found that strategic thinking influences the strategic management practices of an organisation. Additionally, the findings on this variable are consistent with the provisions of the Liedkta model which views strategic thinking from a different perspective to mean thinking about strategy (Feyzollah \& Saeid, 2015). Likewise, Mintzberg (1999) provided that firms that succeed at embedding a capability for strategic thinking throughout their organizations will have created a new source of competitive advantage.

\section{Conclusion}

The study sought to determine the effects of strategic thinking on performance of small and medium-sized dairy processing firms in Kenya. It was established that strategic thinking has a positive significant effect on the performance of small and medium-sized dairy processing firms in Kenya. Therefore, it was perceived that strategic thinking aids creation of a path for what the firm wants to become. Particularly, the performance of small and medium-sized dairy processing firms is guided by the elements of strategic thinking of intent focus, systems perspective, timely thinking, intelligent opportunism, and hypothesis-driven perspective. The intent focus allows persons in a firm to direct their attention towards the firm's goal, to resist distractions and concentrate on the firm goals until they are achieved. A systems perspective involves a firm's attempt to describe the structure in which it exists through the collection of the right information and prioritizing 
the features of the structure that may influence its present and future operations. Thinking in time involves the connection of the past to the present and the future and also learning from the past, then using what was learned to make predictions, and to assess the gap between the present and the future. Intelligent opportunism focuses on the ability to notice and exploit opportunities. The hypothesis-driven perspective involves creating the questions that enables firm to envisage various scenarios and analyse them grounded on their accumulated knowledge.

\section{Recommendations}

Small and medium-sized dairy processing firms in Kenya face a myriad of challenges in the course of operating their businesses. This study concludes that strategic thinking has a positive significant effect on the performance of the small and medium-sized dairy processing firms in Kenya. If well adopted in the firms, then strategic thinking can have important implications for policy and practice that can be used to enhance the performance of small and medium-sized dairy processing firms in Kenya. For instance, strategic leaders of small and medium-sized dairy processing firms in Kenya should enhance the practice of strategic thinking through a systems perspective by describing the structure of the firm and collect the right information, and prioritizing the features of the structure that may influence its present and future operations. Also, strategic leaders should develop and communicate the strategic intent of their firms and allow staff to work towards the firm goals and resist distractions brought about by the industry's dynamics. Particularly, strategic leaders can use intelligent opportunism by noticing and exploiting opportunities in their environment to their advantage, such as incentives from the government to the small and medium-sized enterprises. Moreover, strategic leaders should connect the past to the present and future. This can be done through using the past lessons to make predictions of the future. Moreover, the firms should predict the future by linking the past to the present and the future, envisage scenarios that can help in hypothesizing outcomes and analyse these envisaged scenarios from accumulated knowledge. This should particularly be practiced by strategic leaders in small and medium-sized dairy processing firms because it was found be practiced to a little extent. The findings of the study also provide an empirical model based on adopted conceptual framework which is applicable to the small and medium-sized dairy processing firms. To achieve superior performance, the firms can apply the theoretical model on strategic thinking developed by Leidkta (1998).

The findings and conclusions of this study are, however, limited to the small and medium-sized dairy processing firms in Kenya, therefore future studies should be conducted in the large dairy processing firms in 
Kenya to establish whether similar results will be obtained. Additionally, the study focused on five-year period between 2016 and 2018 therefore, longitudinal studies can be undertaken to establish the effect of strategic thinking in the long-term, on the performance of small and medium-sized dairy processing firms. Other variables such as environmental factors and national policies could be used as moderating and mediating variables to establish their effects on the relationship between strategic thinking and firm performance. Future research should focus on validating the findings and conclusion of this study by undertaking replicative researches in other organizations and sectors in Kenya.

\section{References:}

Ali, F., (2015). The Role of Sustainability in Strategic Thinking in Norwegian Shipbuilding Industry (Master's thesis, NTNU).

Boone, H. N., \& Boone, D. A., (2012) Analyzing Likert Data Journal of extension. Volume 50 Number 2 Article Number 2TOT2

Carter, S. M., \& Greer, C. R. (2013). Strategic leadership: Values, styles, and organizational performance. Journal of Leadership \& Organizational Studies, 20(4), 375-393.

Casey, A.J., \& Goldman, E.F., (2010). Enhancing the ability to think strategically: A learning model. Management Learning 41(2) 167185. DOI: $10.1177 / 1350507609355497$

Di Leo, G., \& Sardanelli, F. (2020). Statistical significance: $p$ value, 0.05 threshold, and applications to radiomics - reasons for a conservative approach. European Radiology Experimental (2020). doi.org/10.1186/s41747-020-0145-y

Emran, F.Z., \& Emamgholizadeh, S. (2015). Strategic Thinking and Its Approaches. Journal of Applied Environmental and Biological Sciences

Field, A. (2013). Discovering statistics using IBM SPSS statistics. Sage.

Food Business Africa, (2015, May 01). Brookside buys Sameer's Uganda dairy operations Africa. https://www.foodbusinessafrica.com/brookside-buys-sameer-suganda-dairy-operations/

Goodman, J. K., Cryder, C. E., \& Cheema, A. (2013). Data collection in a flat world: The strengths and weaknesses of Mechanical Turk samples. Journal of Behavioral Decision-making, 26(3), 213-224.

Hughes, R.L., Beatty, K. C., \& Dinwoodie, D. L., (2014). Becoming a strategic leader: Your role in your organisations success. 2 Edn. John Wiley \& Sons.

Kariuki, A. N., Iravo, M.A., \& Kihoro, J. M., (2015). Access to Resources for Product Diversification and Performance of Informal Dairy 
Enterprises in Kenya. International Journal of Business and Commerce Vol. 4, No.08 [17-33]

Kothari, C.R. (2004). Research Methodology: Methods and Techniques. 2nd Edition, New Age International Publishers, New Delhi.

Kraja, B., \& Osmani, E. (2013). Competitive advantage and its impact in small and medium enterprises: Case of Albania. European Scientific Journal, 9(16), 76-85. DOI: 10.19044/esj.2013.v9n16p\%25p

Kuen, T. K., (2012). The use of midpoint on Likert Scale: The implication for educational research. Hong Kong Teachers' Centre Journal. 11. 121-130.

Lampard, R., \& Pole, C., (2015). Practical Social Investigation: Qualitative and Quantitative Methods in Social Research. Routledge, London.

Lewis, S. (2015). Qualitative inquiry and research design: Choosing among five approaches. Health promotion practice, 16(4), 473-475.

Liedtka, J. M. (1998). Strategic thinking: can it be taught?. Long range planning, 31(1), 120-129.

Mahdavian, M., Mirabi, V., \& Haghshenas, F. (2014). A study of the impact of strategic thinking on the performance of Mashhad municipal managers. Management Science Letters, 4(4), 679-690.

Mintzberg, H., \& Lampel, J. (1999). Reflecting on the strategy process. Sloan management review, 40, 21-30.

Mintzberg, H., (1994). The Rise and Fall of Strategic Planning. New York: Free Press.

Mugenda, A. G. (2008) Social Science Research: Theory and Principles. Acts Press, Nairobi.

Mugenda, D. M., \& Mugenda, A. (2003). Research Methods; Quantitative and Qualitative Research. Nairobi, Kenya. Nairobi acts press.

Ohola, A. L. (2016). Strategic thinking and strategic management practices by Boogaart Betonpompen in Holland (doctoral dissertation, school of business, University of Nairobi).

Olaniyi, I., \& Lucas, E, O. (2016). Strategic Thinking and Organization Performance: Study of Nigeria Firms. Journal of Business Administration Research. DOI: https://doi.org/10.5430/jbar.v5n1p23

Polit, D. \& Beck, C. (2006). The Content Validity Index: Are you sure you know what's being reported? Critique and recommendations. Research in nursing \& health. 29. 489-97. 10.1002/nur.20147.

Robson, K., \& Neuman, L. W., (2014). Basics of Social Research, 3rd Edn. Pearson Canada.

Salih, A. A., \& Alnaji, L. (2014). Impact of Strategic Thinking and Strategic Agility on Strategic Performance: A Case Study of Jordanian Insurance Industry Companies. International Review of Management and Business Research, 3(4), 1871. 
Saunders, M. N. (2011). Research methods for business students, 5th Edn. Pearson Education India.

Saunders, M., Lewis, P. \& Thornhill, A. (2009) Research Methods for Business Students. Pearson, New York.

Sekaran, U., \& Bougie, R., (2010). Research Methods for Business: A skill building approach, 5th Edn, Wiley India (Pvt) Ltd, New Delhi.

Serfontein, J. J., (2010). The impact of strategic leadership on the operational strategy and performance of business organisations in South Africa. A doctoral dissertation presented to the University of Stellenbosch.

Shoemaker, P.J.H., Krupp, S., \& Howland, S., (2013). Strategic Leadership: The Essential Skills. Havard Business Review. January-February 2013

Staal, S.J., Pratt, N. A. \&Jabbar, M., (2008). Dairy development for the resource poor. Part 2: Kenya and Ethiopia. Dairy development case studies. FAO/PPLPI Working Paper, No. 44-2. 52pp. Rome (Italy): FAO.

http://www.fao.org/ag/againfo/programmes/en/pplpi/docarc/wp44_2. pdf

Wambugu, A., \& Kimuyu, P. (2017). Formalization and Technical Efficiency: Evidence from Small Enterprises in Kenya. International Journal of Business and Social Science. DOI: 10.30845/ijbss

Wambugu, S., Kirimi, L. \& Opiyo, J., (2011). Productivity Trends and Performance of Dairy Farming in Kenya. Tegemeo Institute of Agricultural Policy and Development.

Wilson, J. (2010). Essentials of Business Research: A Guide to Doing Your Research Project. SAGE Publications, India. 